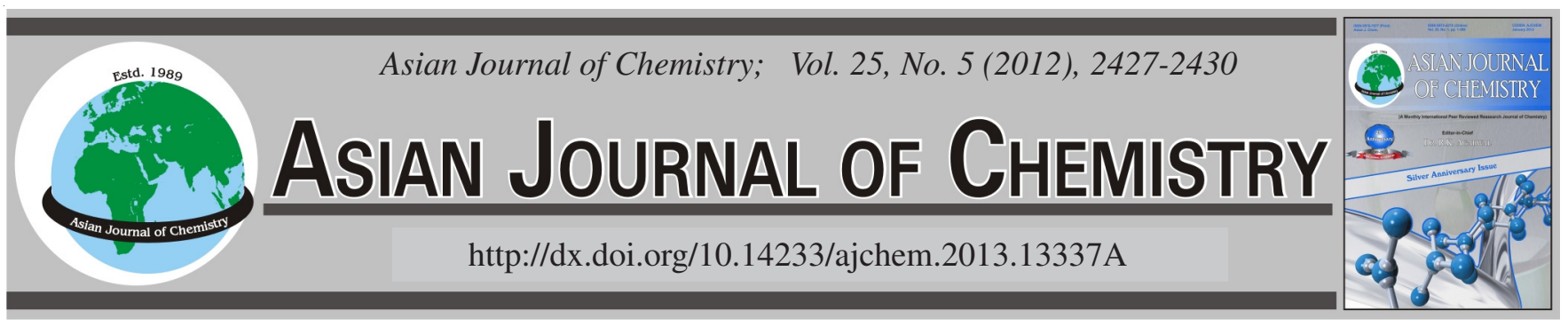

\title{
Comparison of Steam Explosion and Ferric Chloride Solution Pretreatment of Corn Stover: Composition Content, Structural and Enzymatic Hydrolysis
}

\author{
G.M. Zeng, Y.L. WAng*, M.L. Zhang, Y.X. Zheng, J. XING, Y.F. MA and H.J. Xu
}

Key Laboratory of Biorheological Science and Technology for Ministry of Education and Center of Bioinspired Materials Science and Engineering of National "985 Project Program", College of Bioengineering, Chongqing University-Sha Zheng Street, Chongqing, P.R. China

*Corresponding author: E-mail: zeng373064894@126.com

(Received: 27 December 2011;

Accepted: 7 November 2012)

AJC-12373

\begin{abstract}
The efficiency of two lignocellulose pretreatment technologies, steam explosion and ferric chloride solution pretreatment, are compared in terms of composition, structural and enzymatic efficiency with corn stover. Ferric chloride solution pretreatment could easily remove almost all of the hemicelluloses and gain high enzymatic hydrolysis compared with steam explosion, but they both have no effect on delignification and reduced cellulose crystalline. Pretreated material was investigated by X-ray diffraction, scanning electron microscopy and Fourier transform infrared spectroscopy. These results suggested that ferric chloride solution pretreatment may own huge advantages compared to the steam explosion pretreatment process for corn stover. However, the recovery of the ferric chloride solution should also be paid more attention.
\end{abstract}

Key Words: Pretreatment, Steam explosion, Ferric chlori desolution, Comparison, Hemicelluloses.

\section{INTRODUCTION}

In view of the increasing on oil imports and the global warming, renewable biomass resources for bio-ethanol production and fuels have received considerable attention ${ }^{1-3}$. The main structural components of lignocelluloses are cellulose, hemicelluloses and lignin. The presence of lignin and hemicelluloses leads to a protective barrier that prevents lignocelluloses such as corn stover, switchgrass and woody biomass for conversion to bio-energy $y^{4,5}$. The crystallity of cellulose inhibited the efficiency of enzymatic process.

The beneficial effects of pretreatment of lignocellulosic materials have been recognized for a long time. The objective of the pretreatment process is to remove lignin and hemicelluloses, reduce the crystalline of cellulose and increase the porosity of the lignocellulosic materials. Several physical and chemical pretreatment methods are currently employed to overcome the recalcitrance of lignocellulose, increase enzyme efficiency and improve the yields of fermentation. These include steam explosion ${ }^{6}$, dilute acid $^{7-9}$, alkali ${ }^{10,11}$, oxidizing ${ }^{12}$ and organic solvents ${ }^{13,14}$ pretreatment technologies. Among these technologies, steam explosion pretreatment has been extensive used for lignocellulosic materials. During this process, lignocellulosic is treated with high-pressure steam and then the pressure is suddenly released, which makes the materials undergo an explosive decompression. The advantages of steam explosion pretreatment include low costs and energy consumption and it can also increase the cellulose enzyme for removal of hemicelluloses. However, it cannot completely disrupt the lignin-carbodyrate matrix ${ }^{15}$ and decrease the crystallinity of cellulose.

Inorganic molten salts can be used as efficient solvents for lignocellulosic in a wide range of degrees of polymerization. Furthermore, it can also be applied as reaction medium for the derivatization of cellulose $e^{16,17}$. The findings of the investigations indicated that molten salt hydrates are able to dissolve cellulose without pretreatment or activation ${ }^{18}$. Among these molten salt pretreatment, ferric chloride solution pretreatment could easily and effectively transform hemicelluloses into monomeric and oligomeric sugars. It can also significantly damage the surface of corn stover and apparently increased the enzymatic digestability.

The ways of lignocellulosic pretreatment have been studied and compared. No comprehensive comparative analysis has been conducted between steam explosion and ferric chloride solution pretreatment process. Thus, we compare the products after steam explosion and ferric chloride solution pretreatments of corn stover and compare their enzyme efficiency. The primary purpose of this work is to gain a comprehensive understanding of both techniques and evaluate their feasibility for downstream fermentation. Characterization of the treated products, which was recovered from both pretreatment techniques, was investi- 
gated to determine cellulose enzyme and composition contents of corn stover. Structural characteristics including cellulose crystalline and surface morphology were also assessed and compared by using X-ray diffraction (XRD), scanning electron microscopy (SEM) and Fourier transform infrared spectroscopy (FTIR).

\section{EXPERIMENTAL}

Corn stover was collected from Zhong Liang-shan, Chong Qing, China. The air-dried corn stover was milled to powder and screened to an average sizes of 60 -mesh and dried at $105^{\circ} \mathrm{C}$ to avoid influence of the moisture content for use in all experimentations. The cellulose was purchased from Imperial Jade biotechnology company.All chemicals used was of analytical grade. The corn stover was presoaked in distill water at roomtemperature for $10 \mathrm{~h}$ before steam explosion treatment.

\section{General procedure}

Steam explosion pretreatment: The steam explosion experiments were carried out in a bench scale equipment, which consists one steam generator, two pressurized reactor fitted with a quick-opening pressure relief valve and one receivers. Steam explosion operates were carried out using the same amount of corn stover ( $50 \mathrm{~g}$ of dry matter) each batch. After placing the material manually, high temperature steam was applied to reach a predetermined pressure (2.2 $\mathrm{MPa})$. When the expected fixed residence time $(9 \mathrm{~min})$ was reached, the pressure relief valve was auto-opened to release the pressure and then the exploded samples were washed with distilled water five times and then collected and oven-dried at $80^{\circ} \mathrm{C}$ for $24 \mathrm{~h}$. The solid residue was used for further analyses, including enzymatic hydrolysis and structural features.

Ferric chloride solution pretreatment: The dried corn stover was treated under the optimal condition, which was the findings of our previous study, that ferric chloride concentration $0.6 \mathrm{~mol} / \mathrm{L}$, solid-liquid ratio $10: 1$, reaction temperature $170{ }^{\circ} \mathrm{C}$ and reaction time $15 \mathrm{~min}$. The treated sample was washed with deionized water and dried at $80{ }^{\circ} \mathrm{C}$ to evaluate the effects of ferric chloride solution pretreatment and then character for structural features.

Enzymatic hydrolysis: The enzymatic hydrolysis of treated and untreated corn stver were taken in flasks and incubated at $50^{\circ} \mathrm{C}$ on a rotary shaker at $180 \mathrm{rpm} / \mathrm{min}$. Cellulose was purchased from Imperial jade biotechnology Co. (Ningxia, China). Enzymatic hydrolysis of $1 \mathrm{~g}$ pretreated and untreated corn stover was conducted in $24.4 \mathrm{~mL}$ citric acid-sodium citrate buffer solution ( $\mathrm{pH} 4.80$ ) and $0.6 \mathrm{~mL}$ cellulose liquid. Aliquots of $0.5 \mathrm{~mL}$ were removed at different time points $(24,48$ and $72 \mathrm{~h}$ ) and centrifuged at 3,000 rpm for $10 \mathrm{~min}$ and then measuring the release of reducing sugars by DNS assay that uses D-glucose as a standard ${ }^{19}$. All assays are performed in triplicate.

Chemical characterization of corn stover: In the preparation of feed stocks, a two-step extraction process was followed to remove the water-soluble and ethanol-soluble material by the NREL LAP Soxhlet extraction method. After this treatment, three components of lignocellulosics of treated and untreated were determined by Paradigm fiber method.

Crystalline measurement: Crystalline structure of the cellulose sample was determined by X-ray diffraction using a
Rigaku X-ray diffractometer (Rigaku D/MAX 2500PC Japan) with $\mathrm{CuK}_{\alpha}$ radiation $(\mathrm{k}=1.5406 \AA)$; the operation voltage and current were maintained at $40 \mathrm{kV}$ and $150 \mathrm{~mA}$, respectively. The $2 \theta$ range was from $5-50^{\circ}$ in steps of $0.02^{\circ} / 2 \theta$ with continuous scan. Corn stover crystalline, as expressed by crystalline index (Cr I), was determined from XRD data and calculated using the formula ${ }^{20}$ :

$$
\mathrm{Cr} I=\frac{\left(\mathrm{I}_{002}-\mathrm{I}_{\mathrm{am}}\right)}{\mathrm{I}_{002}} \times 100
$$

where $I_{002}$ is the intensity for the crystalline portion of lignocellulosics (cellulose) at ca. $2 \theta=22.5$ and $\mathrm{I}_{\mathrm{am}}$ is the peak for the amorphous portion at about $2 \theta=16.6^{21}$.

Scanning electron microscopy: Scanning electron microscopy was conducted to analyze the micro-structural changes and surface characteristics of untreated and pretreated corn stover. Samples of untreated and treated corn stalk were studied using a TESCAN VEGA II LMU scanning electron microscopy, where samples were coated with a thin layer of gold in an automatic sputter coater before observation. The representative images of untreated and treated by steam explosion and ferric chloride corn stover reported here were acquired with a $10 \mathrm{kV}$ accelerating voltage.

Fourier transform infrared spectroscopy (FTIR) analysis: Fourier transform infrared (FT-IR) spectra were recorded between 4000 and $400 \mathrm{~cm}^{-1}$ using a Spectrum GX (Perkin Elmer, US).

\section{RESULTS AND DISCUSSION}

Component analysis: As Table-1 shown, compared with the untreated materials, steam explosion and ferric chloride solution pretreatment can remove hemicelluloses. But ferric chloride solution pretreatment removes more hemicelluloses and gets more cellulose than steam explosion pretreatment. However, the lignin and ashes of steam explosion and ferric chloride desolution pretreatment were all higher than untreated samples. We hypothesize that the differences in the reported were likely due to the following reasons: (1) During the steam explosion and ferric chloride solution process, the high temperature and incubation time may be efficient to remove the hemicelluloses, (2) the ferric chloride solution may be acting as acid, which can destroy amorphous and remove hemicelluloses, but the crystalline polymorphism was not destroyed. The results confirm that the ferric chloride desolution process could removes more hemicelluloses and small amounts of amorphous cellulose than steam explosion.

TABLE-1

COMPOSITIONAL ANALYSIS OF UNTREATED AND PRETREATED (STEAM EXPLOSION AND FERRIC CHLORIDE) CORN STOVER ${ }^{\mathrm{a}}$

\begin{tabular}{lcccc}
\hline \multicolumn{1}{c}{ Method } & $\begin{array}{c}\text { Cellulose } \\
(\mathrm{g})\end{array}$ & $\begin{array}{c}\text { Lignin } \\
(\mathrm{g} \%)\end{array}$ & $\begin{array}{c}\text { Hemicelluloses } \\
(\mathrm{g})\end{array}$ & $\begin{array}{c}\text { Ashes } \\
(\mathrm{g})\end{array}$ \\
\hline Untreated & 0.151 & 0.041 & 0.166 & 0.002 \\
Steam explosion & 0.240 & 0.055 & 0.164 & 0.004 \\
Ferric chloride & 0.359 & 0.068 & 0.075 & 0.008 \\
\hline
\end{tabular}

${ }^{a}$ Values in parentheses represent the amount of each component recovered from $600 \mathrm{mg}$ total corn stover.

Crystalline index and enzymatic digestability: The crystallinity of the lignocelluloses is believed to be an important 
feature affecting enzymatic hydrolysis of cellulose ${ }^{22,23}$. The XRD was used for studying the features of recovering corn stover after steam explosion and ferric chloride pretreated and also compared to the untreated samples. Results indicated that both steam explosion and ferric chloride solution treated corn stover samples show no decrease in cellulose crystalline, however, they were increase. Fig. 1 showed, the untreated corn stover is highly crystalline (48.9 Cr I) and after steam explosion pretreatment there is a significantly increase in the crystalline index (59.1 Cr I) suggesting that the hemicelluloses breaks down and the lignin soft under the steam explosion process, meanwhile, the inter- and intra- chain hydrogen bondings in cellulose fibrils may regerenation. On the other hand, the ferric chloride solution pretreatment's peak at 22.5 is significantly increased and shifted by 20.1 compared to untreated, which is likely due to the hemicelluloses and other materials in the corn stover removal and the relative content of cellulose increased. The crystalline index calculated from the ferric chloride solution pretreatment sample is significantly higher than both the untreated and steam explosion pretreated samples. This increase in cellulose crystallinity indicates that the recovered product is low amorphous and therefore it has an increase in cellulose surface accessibility and would theoretically enable more efficient cellulose hydrolysis.

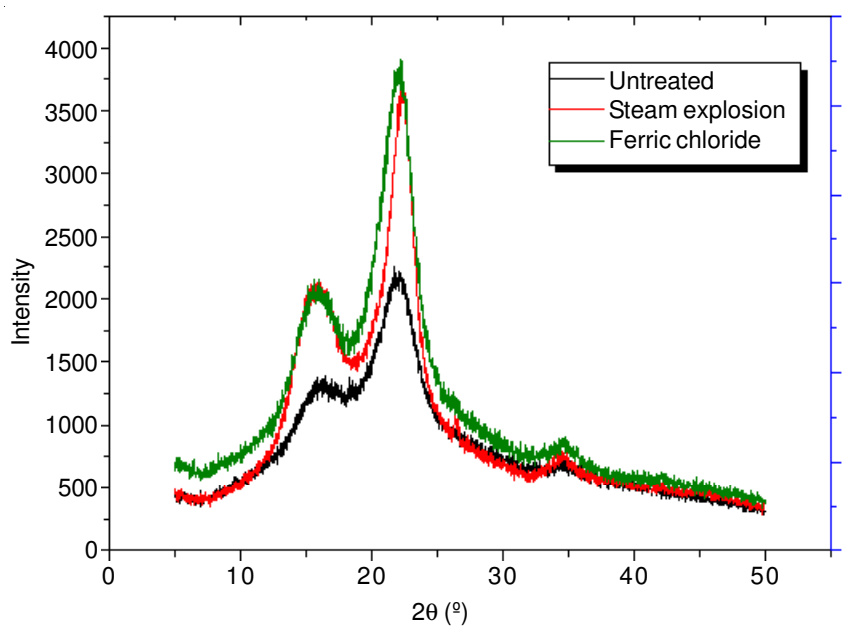

Fig. 1. X-Ray diffractogram of treated corn stover

Enzymatic digestability of untreated, steam explosion and ferric chloride solution treated corn stover to reducing sugar was carried out to compare cellulose digestability. After $72 \mathrm{~h}$ of hydrolysis, Fig. 2 shows total reducing sugar production and cellulose digestability for untreated and pretreated corn stover from steam explosion and ferric chloride solution at the same enzyme loading. Untreated corn stover had cellulose to sugars conversion of $16.1 \%$. During the same period, the cellulose to sugars conversion rates for steam explosion and ferric chloride solution treated material were 72.9 and $91.9 \%$, respectively.

The results from the present study in practice show that the steam explosion and ferric chloride solution can enhance the enzymatic hydrolysis through removal of hemicelluloses. Results from enzymatic hydrolysis also confirmed that the change of the structural of crystalline had exposed the cellulose

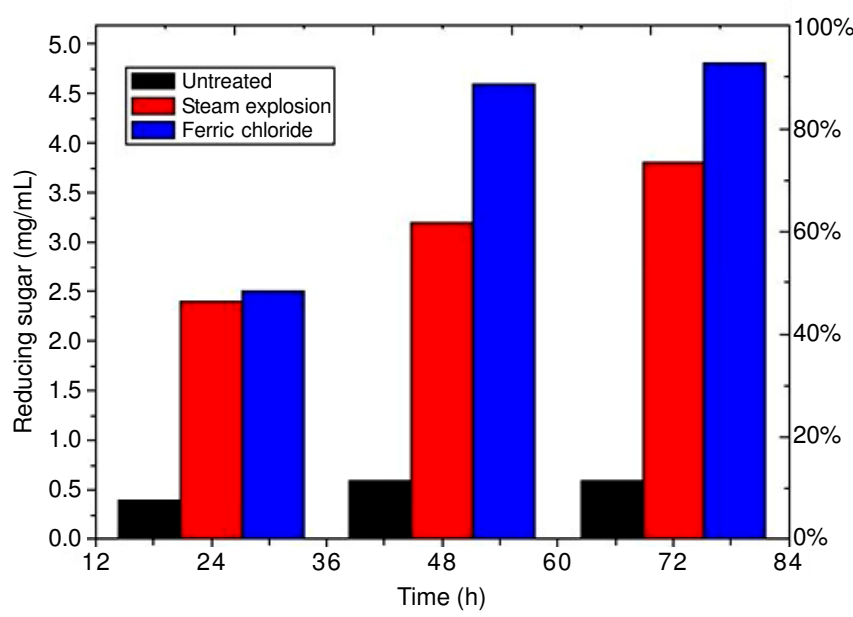

Fig. 2. Comparison of enzymatic saccharification by various pretreatments

fibrils to cellulose and thus improved the enzyme hydrolysis. Based on these observations, it is suggested that ferric chloride solution pretreatment was not only to the removal of hemicelluloses, but also linked with the structure of cellulose changed.

Morphological analysis of corn stover: The SEM micrographs of untreated, steam-exploded and ferric chloride solution treated corn stover were taken at $1000 \times$ magnification (Fig. 3). The results indicated that the surface of untreated corn stover is smooth, highly fibrillar and flat. Small fragments were removed the scales and the surface was damaged by the steam explosion pretreatment. However, the surface was no longer smooth and covered with grooves and ridges indicative of the organization of the microfibrils within the fibers. In contrast, ferric chloride solution pretreatment significantly alters the fibrillar structure. The ferric chloride solution pretreated sample shows the particle size was reduced and more holes and cracks were seen on the surface. These results are consistent with the observations that the pretreated sample was much softer and more available to enzyme hydrolysis than the untreated sample.

FT-IR spectroscopy: Chemical finger printing of steamexplosion and ferric chloride pretreated corn stover and untreated were characterized by FTIR. For comparison to the untreated corn stover spectrum (Fig. 4), the bands at 1380 and $1205 \mathrm{~cm}^{-1}$ decrease significantly for ferric chloride solution pretreated corn stover, whereas the steam explosion materials still show significant presence of hemicelluloses. In addition to that, the peaks at 1320 and $1110 \mathrm{~cm}^{-1}$ (referring to the removal of amorphous cellulose) are decreasing for ferric chloride solution pretreatment, which is consistent with the XRD pattern, indicating that the increase of crystallinity of cellulose. The spectra obtained after steam explosion pretreatment shows an increase of the crystalline cellulose band at $1050 \mathrm{~cm}^{-1}$ and a reduction of the amorphous band at $898 \mathrm{~cm}^{-1}$ compared with untreated. Furthermore, significant decrease of bands intensity are observed at $1160 \mathrm{~cm}^{-1}$ (C-O stretch in cellulose and hemicelluloses), 1335 $\mathrm{cm}^{-1}$ (C-O stretching in lignin and hemicelluloses) and 1375 (C-H deformation in cellulose and hemicelluloses) for the spectra obtained after ferric chloride solution pretreatment, which is likely due to the removal of major hemicelluloses. In comparison, the corresponding bands intensity increase were 


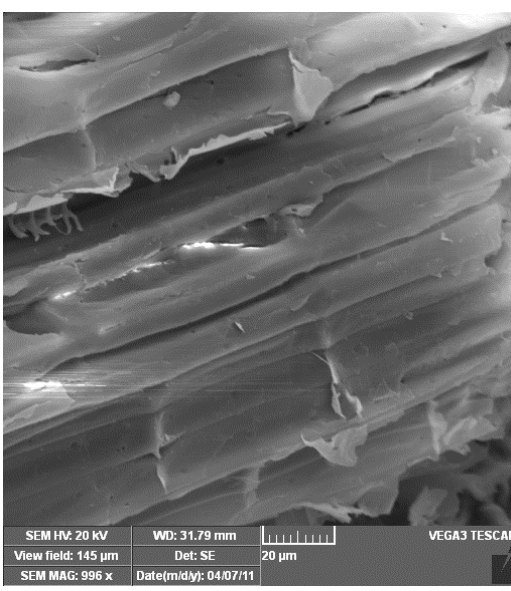

(a)

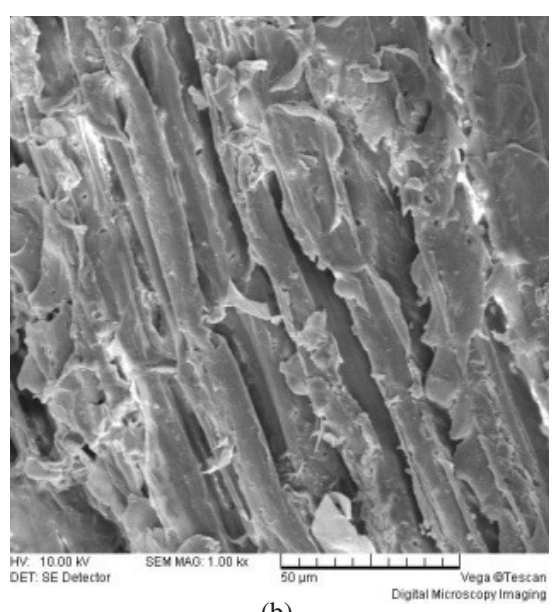

(b)

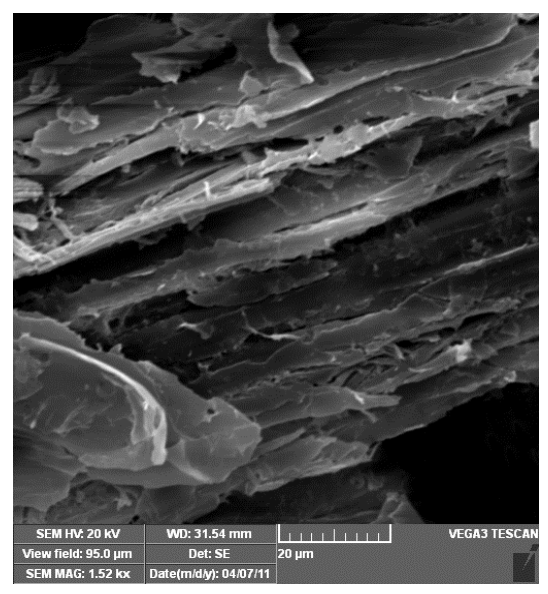

(c)

Fig. 3. SEM images of (a) untreated, (b) steam explosion, (c) ferric chloride pretreated

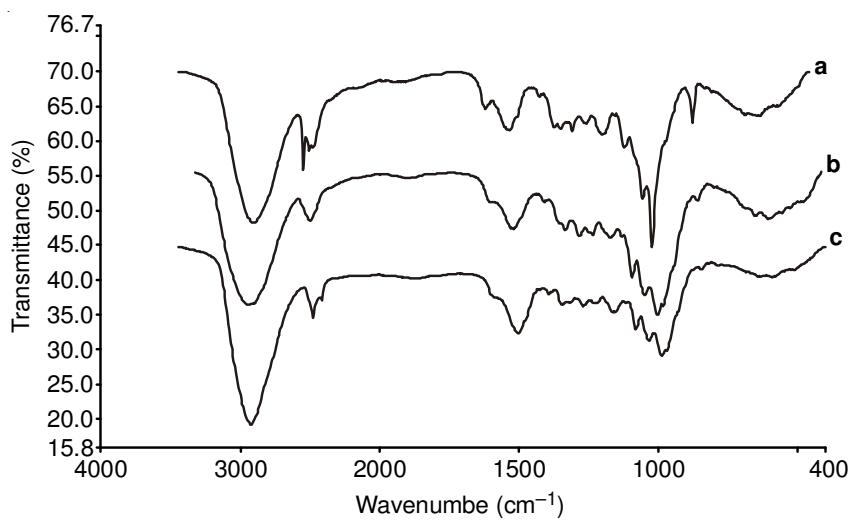

Fig. 4. FTIR sprctra of corn stover; (a) untreated, (b) steamexplosion treated, (c) ferric chloride solution treated

observed in the spectra of ferric chloride solution pretreated samples, which could be attributed to the increase of cellulose content as a result of both amorphous and hemicelluloses removal.

\section{Conclusion}

The methods of pretreatment of lignocelluloses are an extremely fundamental step in a commercial bio-energy, comparison of various pretreatment processes is essential and useful. Comparison of steam-explosion and ferric chloride solution pretreatments of corn stover suggested that the ferric chloride solution pretreatment is a promising superiority to the steam-exploded pretreatment process in terms of removing hemicelluloses and the yield of sugar. Compared with seamexploded pretreatment, the recovered materials from ferric chloride solution pretreatment of corn stover are significantly damaged and enhance the level of enzyme hydrolysis. However, the ferric chloride solution pretreatment is a novel technique and there is much to be discovered before commercial use.

\section{ACKNOWLEDGEMENTS}

This work was supported by grant from the National Natural Science Foundation of China (11032012, 30870609), Natural Science Foundation of CQ CSTC (2009BB4382, 2010BB5225), Science and Technology Program of CQ CSTC (2009AB5174) and Foundation of Chongqing Municipal Education Commission (KJ091415).

\section{REFERENCES}

1. A.V. Bridgwater amd G. Grassi, Biomass Pyrolysis Liquids Upgrading and Utilization, Elsevier Applied Science, London (1991).

2. G. Grassi, G. Gosse and G. dos Santos, Biomass for Energy and Industry, Elsevier Applied Science, London (1990).

3. IEA, World Energy Outlook, OECD/IEA (2008).

4. J.D. Broder, J.W. Barrier, K.P. Lee and M.M. Bulls, World Resour. Rev., 7, 560 (1995).

5. R.D. Perlack, L.L. Wright, A. Turhollow, R.L. Graham, B. Stokes and D.C. Erbach, Biomass as Feedstock for a Bioenergy and Bioproducts Industry: The Technical Feasibility of a Billion-Ton Annual Supply, Oar Ridge National Laboratory, ORNL/TM-2005/66, US Dept. of Energy, Oak Ridge (2005).

6. G. Garrote, H. Dominguez and J.C. Parajó, J. Chem. Technol. Biotechnol., 74, 1101 (1999).

7. K. Grohmann, R. Torget and M. Himmel, Biotechnol. Bioeng. Symp., 15, 59 (1985).

8. T.A. Lloyd and C.E. Wyman, Bioresour. Technol., 96, 1967 (2005).

9. D. Schell, J. Farmer, M. Newman and J. McMillan, Appl. Biochem. Biotechnol., 105-108, 69 (2003).

10. V.S. Chang, B. Burr and M.T. Holtzapple, Appl. Biochem. Biotechnol., 63-65, 3 (1997).

11. S. Singh, B.A. Simmons and K.P. Vogel, Biotechnol. Bioeng., 104, 68 (2009).

12. D. Ben-Ghedalia and J. Miron, Biotechnol. Bioeng., 23, 823 (1981).

13. W.J. Connors, L.N. Johanson, K.V. Sarkanen and P. Winslow, Holzforschung, 34, 29 (1980).

14. Y.H.P. Zhang, S.Y. Ding, J.R. Mielenz, J.B. Cui, R.T. Elander, M. Laser, M.E. Himmel, J.R. McMillan and L.R. Lynd, Biotechnol. Bioeng., 97, 214 (2007).

15. B.M. Cherian, L.A. Pothan, T.N. Chung, G. Mennig, M. Kottaisamy and S. Thomas, J. Agric. Food Chem., 56, 5617 (2008).

16. S. Fischer, W. Voigt and K. Fischer, Cellulose, 6, 213 (1999).

17. H. Leipner, S. Fischer, E. Brendler and W. Voigt, Macromol. Chem. Phys., 201, 2041 (2000).

18. S. Fischer, H. Leipner, E. Brendler, W. Voigt and K. Fischer, ACS Symp. Ser., 737, 143 (1999).

19. G.L. Miller, Anal. Chem., 31, 426 (1959).

20. L. Segal, J.J. Creely, A.E. Martin Jr. and C.M. Conrad, Textile Res. J., 29, 786 (1959).

21. R. Kumar, G. Mago, V. Balan and C.E. Wyman, Bioresour. Technol., 100, 3948 (2009)

22. A.P. Dadi, C.A. Schall and S. Varanasi, Appl. Biochem. Biotechnol., 137, 407 (2007).

23. R. Kumar, G. Mago, V. Balan and C.E. Wyman, Bioresour. Technol., 100, 3948 (2009). 